\title{
Emergency treatment of adder bites: case reports and literature review
}

\author{
D. J. HARBORNE \\ Department of Accident \& Emergency Medicine, Basingstoke District Hospital, \\ Basingstoke, Hampshire
}

\section{SUMMARY}

Five cases of adder bites are presented. The clinical effects and current recommendations for the treatment of adder bites are described based on a review of previously published literature. All adder bites, or snake bites of unknown species, should be observed for a minimum of $2 \mathrm{~h}$. Those with no local swelling may be allowed home with appropriate antitetanus prophylaxis. Patients with local reaction or signs of systemic envenoming should be admitted for $48 \mathrm{~h}$ with ECG monitoring, and antivenom obtained. Indications and precautions for administration of antivenom are reviewed. Early antivenom treatment may reduce mortality and morbidity from adder bites.

\section{INTRODUCTION}

Vipera berus, the European adder, is Britain's only native venomous snake and is distinguishable by a dorsal zigzag pattern and a V-shaped marking on the head. Adder bites are an infrequent cause of hospital attendance, although patients may fail to seek medical attention (Persson \& Irestadt, 1981). There is a peak of adder bites in the summer months, usually in the upper limbs of males who interfere with the snake (Walker, 1945; Reid, 1976). The majority of patients are below the age of 15.

Only 14 cases of fatality had been recorded in the U.K. between 1876 and 1976 (Reid, 1976), but up to $50 \%$ of recorded cases have had significant local or systemic toxicity. A summary of clinical signs and symptoms with a classification of the severity of bite is summarized in Tables 1 and 2.

The clinical effects of adder bites are due to large molecular weight proteins

Correspondence: D. J. Harborne Senior Registrar in Accident \& Emergency, Basingstoke District Hospital, Aldermaston Road, Basingstoke, Hampshire RG24 9NA, U.K. 
Table 1. Clinical features of adder bite

(1) Local (95\%): oedema and haemorrhage spreading over 2-3 days, swelling persistent over 2-3 weeks. Regional lymphadenopathy.

(2) Gastrointestinal (24\%): vomiting, abdominal colic, diarrhoea.

(3) Cardiovascular: hypotension (20\%), sweating, ECG changes (T-wave flattening, arrhythmias $3 \%$ ).

(4) Laboratory: leucocytosis (30\%), raised CPK, thrombocytopenia (3\%).

(5) Fever (5\%).

(6) Depressed level of conciousness (5\%).

(7) Pulmonary (3\%) bronchospasm, pulmonary oedema, pulmonary haemorrhage.

Table 2. Classification of adder bites by severity (after Reid)

(A) Minor: no local swelling

(B) Mild: local swelling $+/-$ gastrointestinal symptoms

(C) Moderate: extensive oedema $+/-$ shock $<2 \mathrm{~h}$

(D) Severe: shock $>2 \mathrm{~h}$ or other signs of systemic envenoming

(E) Fatal

which are taken up into lymphatics, initially, and then enter the systemic circulation. Hypovolaemia and local oedema is due to increased vascular permeability, at first due to the release of kinins, but later due to a direct effect of venom on the heart and blood vessels (Warrell, 1987). Local haemorrhage is probably due cytolytic and haemolytic factors.

\section{CASE REPORTS}

Case 1

A 12-year-old boy was bitten on the finger by an adder in the Forest of Dean. There was no local reaction after $4 \mathrm{~h}$. He was discharged with oral antibiotics after tetanus prophylaxis.

\section{Case 2}

A 10-year-old girl was bitten on her right middle finger by an adder in woodland. No local reaction was observed after $4 \mathrm{~h}$. She was discharged on oral antibiotics.

\section{Case 3}

A 2-year-old boy was bitten on his right index finger in a Portsmouth garden. The ? dead adder was brought to the accident and emergency (A\&E) department for $\tilde{N}$ identification. The child developed bruising and swelling of the finger and hand within $30 \mathrm{~min}$ of the bite. He was treated with oral antihistamines and steroids, and admitted for ECG monitoring, but had no systemic signs of envenoming over the following $48 \mathrm{~h}$. 


\section{Case 4}

A 13-year-old boy was bitten by an adder he was teasing outside a country pub. The dead snake was brought for identification. On arrival at the accident unit, some $25 \mathrm{~min}$ after the bite, he was pale, sweaty, confused and had a fine allergic rash over both upper arms. There was a $2 \mathrm{~cm}$ diameter area of bruising over the volar aspect of the right thumb with swelling of the hand and arm to just below the elbow. There was a sinus tachycardia of $130 \mathrm{~min}^{-1}$ and blood pressure dropped from $110 / 70$ to $80 / 50 \mathrm{mmHg}$. The patient was treated with 11 of gelofusine over $30 \mathrm{~min}$, intravenous hydrocortisone and chlorpheniramine. Within $2 \mathrm{~h}$ of the bite he developed diarrhoea and vomiting and the oedema reached the chest wall. Results of routine biochemistry were normal, but coagulation studies showed a raised $\mathrm{D}$ dimer level $>2500 \mathrm{ngl}^{-1}$ (equivalent to increased FDP level), and there was a leucocytosis of $14.8 \times 10^{9} 1^{-1}$.

Three hours after the bite $4.5 \mathrm{ml}$ of Zagreb* antivenom was infused intravenously (the remainder of available antivenom had been used for Case 5). The patient then rapidly lost signs and symptoms of systemic envenoming. Residual haemorrhagic oedema of the right arm (Fig. 1) took 2 weeks to resolve.

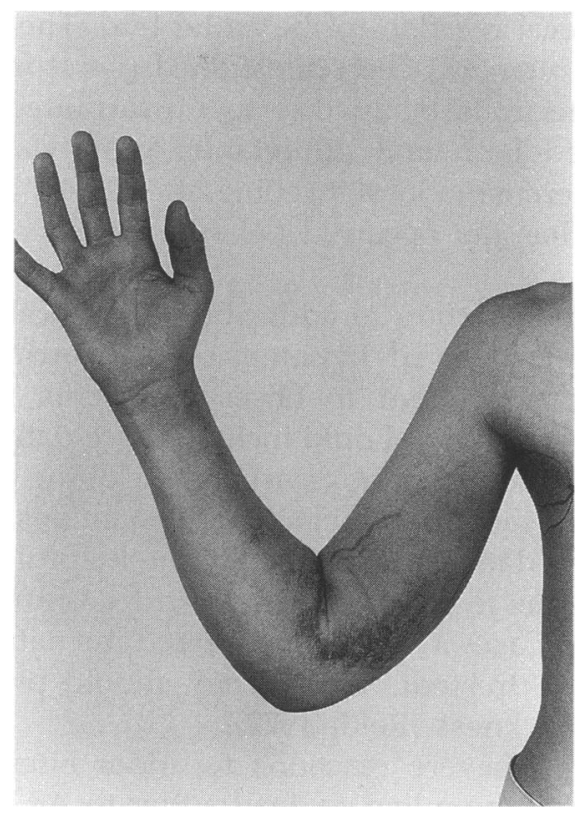

Fig. 1. Residual haemorrhagic oedema of the right arm.

\footnotetext{
* Zagreb antivenom is supplied by Regent Lab, 861 Coronation Road, Park Royal, London NW10 7PT. Batches are tested by the Department of Health for quality before being placed in several pharmacies within each region. Hospitals should be able to obtain supplies at short notice.
} 


\section{Case 5}

A previously fit 64-year-old man was bitten by an adder when he moved the्ष. snake out of the path of his car. He arrived in the accident unit some $30 \mathrm{~min}$ after the bite and $2 \mathrm{~h}$ after Case 4 . He was accompanied by a live adder in a carrief bag. On examination he had a bite mark on his right hand with oedema of his hand and fingers spreading up the forearm. He was sweaty and hypotensive with a blood pressure of 95/60. ECG showed ST depression in V5 and V6. Routine biochemistry and haematology with clotting studies showed no abnormalitieङ apart from a mild thrombocytopenia. The patient was treated initially with $200 \mathrm{mg}$ hydrocortisone, $10 \mathrm{mg}$ chlorpheniramine and 11 of gelofusine but his blood pres:sure failed to rise over the course of the following hour. He was then given $9 \mathrm{ml}$ of Zagreb antivenom intravenously and became normotensive, pink and dry over the following $5 \mathrm{~min}$. He then made a full recovery with the swelling slowly resolving over the following 14 days. He had a transitory itchy rash on day 7 , possibly due to a mild form of serum sickness.

\section{DISCUSSION}

Cases 1, and 2 had no local reaction to the adder bite. The value of oral antibio迎 prophylaxis after snake bites has been questioned (Persson \& Irestedt, 1981), the majority of bacterial infections being due to unwarranted surgical interferenes Splintage of the affected limb and antitetanus prophylaxis are the only loogib treatment required. If there is no local swelling after $2-4 \mathrm{~h}$ it is safe to assume that significant envenoming has not occurred (Warrell, 1987), and the patient may be discharged.

Case 3 illustrates a mild reaction to adder bite with local swelling but no signs of systemic toxicity. Since delayed hypotension and arrhythmias (Moore, 1988) $\overrightarrow{\mathbb{E}}$ have been described it is prudent to observe patients for $48 \mathrm{~h}$, initially with ${ }^{3}$ cardiac monitoring. Investigations should include twice daily urea and electrolytes full blood count, creatinine phosphokinase and clotting studies. The value of antihistamines and steroids is questionable. Antihistamines may help early allergiẹ. rashes (Case 4) and the sedative properties may be helpful in children. Most loca马 and systemic effects are due to direct toxicity of adder venom, and the widespread use of steroids (including Cases 3-5) has not altered the natural history of reactionş to adder bites (Persson \& Irestedt, 1981). They should probably be reserved foro treatment of late serum sickness (Reid, 1972).

Cases 4 and 5 illustrate severe reactions to adder bites with severe systemic signs and symptoms. Bringing a live or dead adder to A\&E is not recommended N as second bites have been reported up to an hour after a snake head has been severed from the body (Reid, 1976). It can be assumed in this country that any immediate swelling from a snakebite or toxicity is due to the adder as this iso Britain's only venomous snake.

Administration of colloid is the mainstay of treatment of early hypotension both Cases 4 and 5 were resuscitated with gelofusine. Antivenom was used in both cases, with marked clinical improvement. There is both experimentab 
Table 3. Antivenom treatment

Indications

(1) Hypotension persists $>2$ hours despite IV fluids

(2) Leucocytosis $>20 \times 101^{-9}$

(3) ECG changes

(4) Acidosis

(5) Raised CPK level

(6) Local swelling in an adult seen within $2 \mathrm{~h}$, or swelling at any age extending up the forearm or leg. Contraindications

(1) Hypersensitivity to horse serum.

(2) Atopic/allergic history (relative contraindication).

Dose

2 vials $(9 \mathrm{ml})$ of Zagreb antivenom intravenously diluted in $100 \mathrm{ml} 0.9 \%$ saline over $30-60 \mathrm{~min}$. The antivenom dose is the same for all ages. Adenaline should be available to treat possible reactions.

(Theakston \& Reid, 1976) and clinical (Cederholm \& Lennmarken, 1987) evidence that early administration of antivenom reduces mortality and morbidity. Antivenom administered to envenomed Rhesus monkeys saved them from death and reduced subsequent local swelling. Local swelling may be prolonged in humans, especially adults, and early antivenom treatment may reduce severity of oedema and time to complete recovery. Until recently, antivenom treatment was unpopular in this country due to a single death in 1956 from anaphylaxis after administration of Pasteur antivenom. The newer, more active, and purer Zagreb antivenom is now sanctioned by the British National Formulary. Current indications and administration of Zagreb antivenom (Reid, 1976) are reviewed in Table 3.

Case 4 is unusual as clotting abnormalities have not previously been documented with adder bites, but are a common feature of envenoming by other vipers. The $D$ dimer test is much more sensitive for fibrinolysis than the previous FDPs.

\section{ACKNOWLEDGEMENTS}

The author would like to thank Dr R. Guy, Dr B. Elvin, Dr R. Walters and Mr G. Carss for permission to report their patients.

\section{REFERENCES}

Cederholm I. \& Lennmarken C. (1987) Vipera berus bites in children, experience of early antivenom treatment. Acta Paediatrica Scandinavica 76, 682-684.

Moore R. (1988) Second degree heart block associated with envenomation by Vipera berus. Archives of Emergency Medicine 5, 116-118.

Persson H. \& Irestedt B. (1981) A study of 136 cases of adder bite treated in Swedish hospitals during one year. Acta Medica Scandinavica 210, 433-439.

Reid H. (1976) Adder bites in Britain. British Medical Journal 2, 153-156.

Theakston R. \& Reid H. (1976) Effectiveness of Zagreb antivenom against envenoming by the adder, Vipera berus. The Lancet 2, 121-123.

Walker C. (1945) Notes on adder bite (England and Wales) British Medical Journal 2, 13-14.

Warrell D. (1987) Oxford Textbook of Medicine, Vol. 6 pp. 70. Oxford University Press, Oxford. 